\title{
Physiological function analysis of Lactobacillus plantarum Y44 based on genotypic and phenotypic characteristics
}

\author{
Yuan Gao, ${ }^{1,2} \oplus$ Yujun Liu, ${ }^{1} \oplus$ Mengying Sun, ${ }^{1,2}$ Heping Zhang, ${ }^{1,3} \odot$ Guangqing Mu, ${ }^{1,2 *} \odot$ and Yanfeng Tuo ${ }^{1,2 *}$ () \\ ${ }^{1}$ School of Food Science and Technology, Dalian Polytechnic University, Dalian 116034, China \\ 2Dalian Probiotics Function Research Key Laboratory, Dalian Polytechnic University, Dalian 116034, China \\ ${ }^{3}$ Key Laboratory of Dairy Biotechnology and Engineering, Ministry of Education, Inner Mongolia Agricultural University, Hohhot 010018 , China
}

\begin{abstract}
In our previous studies, Lactobacillus plantarum Y44 showed antioxidant activity and favorable gastric and intestinal transit tolerance. In the current study, we investigated the physiological function of $L$. plantarum Y44 based on an analysis of its genotype and phenotype. The complete genome of $L$. plantarum Y44 contained a single circular chromosome of $3,255,555 \mathrm{bp}$, with a GC content of $44.6 \%$, and a single circular plasmid of $51,167 \mathrm{bp}$, with a GC content of $38.8 \%$. The L. plantarum Y44 genome contained 3,293 genes including 3,112 protein coding sequences, 16 rRNAs, 66 tRNAs, 4 small (s)RNAs, and 95 pseudo genes. Lactobacillus plantarum Y44 could metabolize 24 different carbohydrate sources. Nineteen complete phosphoenolpyruvate-dependent sugar phosphotransferase system complex genes and intact Embden-Meyerhof-Parnas pathway and hexose monophosphate pathway enzyme genes, as well as abundant carbohydrate active enzyme genes, were identified in the L. plantarum Y44 genome. We also identified genes related to the biosynthesis of exopolysaccharide and surface proteins. Surface proteins played an important role in the L. plantarum Y44 adhesion to HT-29 cell monolayers, as evidenced by the removal of cell surface proteins leading to decreased adhesion capacity. The L. plantarum Y44 genome contained genes encoding chaperones, intracellular proteases, and 2-component systems, which were associated with the general stress response. Genes encoding bile salt hydrolase, $\mathrm{F}_{0} \mathrm{~F}_{1}$-ATPase, $\mathrm{Na}^{+} / \mathrm{H}^{+}$-antiporter, $\mathrm{H}^{+} / \mathrm{Cl}^{-}$exchange transporter, cyclopropane-fatty acyl-phospholipid synthase, and alkaline shock protein were identified in the L. plantarum Y44 genome, which might explain the
\end{abstract}

Received December 11, 2019.

Accepted March 5, 2020.

*Corresponding authors: gq6552005@aliyun.com and tyfjq@aliyun com strain's favorable gastric and intestinal transit tolerance. Some genes associated with encoding the NADH system, glutathione system, and thioredoxin system were predicted via in silico analysis and might account for the strain's ability to scavenge reactive oxygen species. Lactobacillus plantarum Y44 was susceptive to 7 antibiotics and did not produce biogenic amines, likely due to the absence of acquired antibiotic resistance genes and amino acid decarboxylase genes. The phenotype profile of $L$. plantarum Y44 was associated with its genetic characteristics, indicating that strains with certain physiological functions can be screened by analyzing their phenotypic and genotypic characteristics. Lactobacillus plantarum Y44 has the potential to be used as a starter culture in fermented dairy products.

Key words: Lactobacillus plantarum, probiotics, complete genome sequence, phenotype, genotype

\section{INTRODUCTION}

Lactobacillus plantarum, which is used to produce dairy products such as cheese, kefir, and yogurt (Todorov and Franco, 2010), is an extremely versatile species that offers various beneficial properties to humans (Seddik et al., 2017). It has the qualified presumption of safety status from the European Food Safety Authority (EFSA) and a generally recognized as safe status from the US Food and Drug Administration. In our previous study, L. plantarum Y44 exhibited favorable gastric and intestinal transit tolerance, as well as the ability to scavenge reactive oxygen species (ROS) and protect human colon cancer cell lines Caco-2 and HT29 against ROS injury (Mu et al., 2018, 2019).

The development of high-throughput genomic approaches has led to a deep understanding of the beneficial properties and applications of lactobacilli. The next-generation sequencing enables a better understanding of physiological properties and applications of Lactobacillus strains, including their genes, safety, metabolic properties, and ecological roles (Satokari, 
2019; Suez et al., 2020). The EFSA has developed guidance (EFSA FEEDAP Panel et al., 2018) for using a microorganism's genome to unequivocally characterize its antibiotic sensitivity, production of toxic metabolites (i.e., biogenic amines), toxicity, and pathogenicity. Rodrigo-Torres et al. (2019) analyzed safety and biotechnological potential of different L. plantarum strains through complete genome comparison. Lactobacillus rhamnosus GR-1 was genetically and experimentally predicted to be adapted to the vaginal environment (Petrova et al., 2018). Fei et al. (2018) confirmed the ability of Lactobacillus amylolyticus L6 to use raffinose and stachyose by complete genome sequencing and phenotype analysis. Using genomic comparison and corresponding phenotype analysis, Fontana et al. (2019) found that Lactobacillus helveticus was adapted to dairy niches, as evidenced by its containing maltosedegrading enzymes and multiple copies of 6 -phospho- $\beta$ glucosidase genes.

Lactobacillus plantarum Y44 has shown favorable stress tolerance and potential applications in commercial dairy products. Before such commercial applications are undertaken, however, the genotypic and phenotypic characteristics of L. plantarum Y44 should be clarified. In this study, we sequenced the complete genome of $L$. plantarum Y44, using the PacBio RS II platform, and performed gene predication and annotation in silico. We also determined phenotypic characteristics, including the carbohydrate utilization profile, bile salt hydrolase (BSH) activity, adhesion capacity to HT-29 cells, antioxidant enzyme activity, antibiotic susceptibility, and the production of biogenic amines. Finally, we analyzed the association between the phenotypic characteristics and the genome of L. plantarum Y44.

\section{MATERIALS AND METHODS}

\section{Bacterial Strains and Growth Conditions}

Lactobacillus strains tested in this study were stored in de Man, Rogosa, and Sharpe (MRS) broth medium (Land Bridge Technology, Beijing, China) containing $25 \%$ glycerol at $-80^{\circ} \mathrm{C}$ in Dalian Probiotics Function Research Key Laboratory. Lactobacillus plantarum Y44, L. plantarum ATCC 14917, and L. rhamnosus GG (ATCC 53103) were cultured in MRS broth (Land Bridge Technology) at $37^{\circ} \mathrm{C}$ for $18 \mathrm{~h}$ twice before use.

\section{Genomic DNA Isolation and Single Molecule, Real-Time Sequencing}

Genomic DNA was extracted using a Wizard Genomic DNA Purification Kit (Promega, Madison, WI) according to the manufacturer's instructions. The concentration and purity of genomic DNA were measured by a Qubit 2.0 Fluorometer (Thermo Fisher Scientific, Waltham, MA) and electrophoresis on a $0.7 \%$ agarose gel. Sequencing libraries with an average insert size of $20 \mathrm{~kb}$ were constructed, and the genomic DNA was sequenced on a PacBio RS II platform (Pacific Biosciences, Menlo Park, CA) with P6-C4 chemistry (Eid et al., 2009). The raw reads were filtered and de novo assembled by the hierarchical genome-assembly process (Chin et al., 2013).

\section{Bioinformatic Analysis}

The complete genome of L. plantarum Y44 was annotated by National Center for Biotechnology Information (NCBI) Prokaryotic Genomes Automatic Annotation Pipeline (PGAAP; Tatusova et al., 2016). A circular genome map of $L$. plantarum Y44 was visualized by CGview (Stothard and Wishart, 2005). Average nucleotide identity values of $L$. plantarum Y44 compared with other L. plantarum strains were calculated using JSpeciesWS (Richter et al., 2016). Carbohydrate active enzyme genes (CAZymes) were searched against the CAZy database (Lombard et al., 2014). The metabolic pathways of $L$. plantarum Y44 were predicted by KofamKOALA to search against the KEGG database (Aramaki et al., 2019). The presence of antibiotic resistance genes was detected using the Resfams and CARD database (Gibson et al., 2015; Jia et al., 2017b). ResFinder was used for detecting acquired antibiotic resistance genes (Zankari et al., 2012). The sequences and annotations of other strains analyzed in this study were obtained from the NCBI database (http://www .ncbi.nlm.nih.gov).

\section{Carbohydrate Utilization Profile}

The carbohydrate utilization profile of $L$. plantarum Y44 was tested with an API 50 CHL kit (bioMérieux SA, Marcy-l'Étoile, France) and 49 selected carbohydrate sources following the manufacturer's instructions, with L. plantarum ATCC 14917 as the control.

\section{BSH Activity}

The BSH activity of $L$. plantarum Y44 was assessed as described by Beck et al. (2019). Lactobacillus plantarum Y44 was streaked on MRS agar containing $0.5 \%$ taurodeoxycholic acid (wt/vol) (TDCA, Aladdin, Shanghai, China) or $0.5 \%$ glycodeoxycholic acid (GDCA, Aladdin) and anaerobically incubated at $37^{\circ} \mathrm{C}$ for $48 \mathrm{~h}$. Deconjugation of TDCA or GDCA resulted 
in a white precipitate of deoxycholate in the vicinity of bacterial colonies with BSH activity. Lactobacillus rhamnosus GG was used as a positive control.

Quantitative determination of the BSH activity was done by measuring the liberation of amino acids (glycine or taurine) from TDCA or GDCA, as described by Fontana et al. (2019). Bile salt hydrolase activity was expressed in units per milliliter because 1 unit of BSH activity was defined as the amount of enzyme that liberated $1 \mathrm{mmol}$ of glycine (TDCA as substrate) or taurine (GDCA as substrate) per minute.

\section{Capacity for Adhesion to HT-29 Cells}

Human colon cancer cells (line HT-29, Cell Bank of the Type Culture Collection of the Chinese Academy of Sciences, Shanghai, China) were routinely cultured at $37^{\circ} \mathrm{C}$ in a $5 \% \mathrm{CO}_{2}$ atmosphere in RPMI-1640 medium (Gibco Life Technologies, Grand Island, NY) supplemented with $10 \%$ (vol/vol) fetal bovine serum (Gibco Life Technologies), $100 \mathrm{U} / \mathrm{mL}$ penicillin, and $100 \mathrm{mg} / \mathrm{mL}$ streptomycin (Meilun Biotechnology, Dalian, China).

The adhesion capacity of $L$. plantarum Y44 to HT29 cells was investigated according to the method described by Lee et al. (2016b), with some modifications. Briefly, HT-29 cells were seeded at a density of $2 \times 10^{5}$ cells/well on a 12-well microplate (Corning Inc., Corning, NY) in $1 \mathrm{~mL}$ of RPMI-1640 medium at $37^{\circ} \mathrm{C}$ for 48 $\mathrm{h}$ to form cell monolayers. Lactobacillus plantarum $\mathrm{Y} 44$ was resuspended in RPMI-1640 medium to a final concentration of $5 \times 10^{8} \mathrm{cfu} / \mathrm{mL}$, and $1 \mathrm{~mL}$ of the suspension was added to each well of the 12-well microplate. After a 2-h incubation, the cells were washed 5 times with PBS (pH 7.4, Gibco Life Technologies) to remove nonadherent bacteria. HT-29 cells were lysed by the addition of $0.5 \%$ (vol/vol) Triton-X100 (Solarbio Life Science, Beijing, China), and adherent viable counts of L. plantarum Y44 were determined by a pour plate method using MRS agar after incubation for $48 \mathrm{~h}$ at $37^{\circ} \mathrm{C}$. The adhesion capacity was defined as the number of adhered bacterial cells per HT-29 cell. Lactobacillus rhamnosus GG was used as a positive control.

The adhesion ability of the L. plantarum Y44 to HT-29 cells was also evaluated considering the effect of their cell surface proteins. Cell surface proteins of $L$. plantarum Y44 were removed by mixing with $\mathrm{LiCl}(5$ $M$ ) and incubating at $37^{\circ} \mathrm{C}$ for $30 \mathrm{~min}$. The mixture was then centrifuged $\left(5,000 \times g, 10 \mathrm{~min}, 4^{\circ} \mathrm{C}\right)$ to remove the supernatant. The viable counts of $\mathrm{LiCl}$-treated L. plantarum Y44 were determined by a pour plate method using MRS agar after serial dilution in maximum re- covery. The bacterial cells were washed twice with PBS and resuspended in RPMI-1640 medium (Gibco Life Technologies) to a final concentration of $5 \times 10^{8} \mathrm{cfu} /$ $\mathrm{mL}$ for the assay of the ability to adhere to HT-29 cells as described above.

\section{Superoxide Dismutase and Glutathione Peroxidase Activity Assay}

The superoxide dismutase (SOD) and glutathione peroxidase $(\mathbf{G P x})$ activities were determined using the detection kit provided by Nanjing Jiancheng Bioengineering Institute (Nanjing, China) according to the manufacturer's instruction.

\section{Antibiotic Susceptibility}

The antibiotics ampicillin, vancomycin, gentamicin, kanamycin, erythromycin, clindamycin, tetracycline, and chloramphenicol (Sangon Biotech, Shanghai, China) were chosen for antibiotic susceptibility testing of lactobacilli according to EFSA FEEDAP Panel et al. (2018). Minimum inhibitory concentration was determined using the standard microdilution method for Lactobacillus antibiotic susceptibility testing as reported in the ISO10932/IDF233 2010 document (International Dairy Federation, 2010). Briefly, each antibiotic was carefully weighed, dissolved in the appropriate solvent, filter-sterilized $(0.22 \mu \mathrm{m}$, Merck Millipore, Darmstadt, Germany), and kept at $-80^{\circ} \mathrm{C}$ as a stock antibiotic solution. Specific concentrations of antibiotic working solutions were prepared by serial 2 -fold dilution of stock antibiotic solutions, and the concentration range was selected according to the ISO10932/IDF233 2010 document. Overnight Lactobacillus cultures were adjusted to approximately $3 \times 10^{8} \mathrm{cfu} / \mathrm{mL}$ in lymphocyte separation medium (LSM; ISO-Sensitest broth, Oxoid, Basingstoke, UK, supplemented with 10\% vol/ vol MRS broth). Then, the bacterial suspension was diluted 500 times in LSM and mixed with the antibiotic working solutions. The mixture was incubated at $28^{\circ} \mathrm{C}$ for $48 \mathrm{~h}$. The MIC was defined as the lowest concentration of an antibiotic that prevented visible growth of a test organism in a broth microdilution method under the conditions specified in the ISO10932/IDF233 2010 document (International Dairy Federation, 2010). The quality control strain L. plantarum ATCC 14917 included in that document was used for comparisons and interlaboratory range analysis. Antibiotic susceptibility of L. plantarum Y44 was calculated according to microbial cutoff values $(\mu \mathrm{g} / \mathrm{mL})$, as recommended by EFSA FEEDAP Panel et al. (2018). 


\section{Production of Biogenic Amines}

Decarboxylase medium plate was prepared according to the method described by Bover-Cid and Holzapfel (1999). Lactobacillus plantarum Y44 was cultivated 5 times in MRS broth (Land Bridge Technology) supplemented with $0.1 \%$ (wt/vol) of each amino acid (tyrosine, histidine, ornithine, lysine, tryptophan, phenylalanine, and arginine, respectively; Solarbio Life Science) and $0.005 \%$ pyridoxal-5-phosphate (Solarbio Life Science) for $24 \mathrm{~h}$ to induce decarboxylase expression. Then, 10 $\mu \mathrm{L}$ of the bacterial suspension was inoculated onto the decarboxylase medium plate and incubated for $96 \mathrm{~h}$ at $37^{\circ} \mathrm{C}$. The appearance of a purple color on the decarboxylase medium plate indicated that the strain could produce biogenic amines (Chang and Chang, 2012). Lactobacillus rhamnosus GG was used as the control.

\section{Statistical Analysis}

All tests were performed in triplicate. Data are presented as mean \pm standard deviation. One-way ANOVA was performed with SPSS (Version 20.0, SPSS Inc.,
Chicago, IL) to verify significant differences between samples. The results were considered significant at $P$ $<0.05$.

\section{RESULTS AND DISCUSSION}

\section{General Genome Features of L. plantarum Y44}

The complete genome of L. plantarum Y44 consisted of a circular chromosome of 3,255,555 bp and a 51,167-bp plasmid, named pY44-1, as shown in Figure 1 and Table 1. A total of 3,194 genes were predicted by PGAAP, including 3,013 protein coding sequences, 16 rRNAs, 66 tRNAs, 4 sRNAs, and 95 pseudo genes. The average nucleotide identity values of different $L$. plantarum strains are shown in Figure 2. Lactobacillus plantarum Y44 clustered with L. plantarum ssp. plantarum ST-III (L. plantarum ST-III) and L. plantarum CAUH2, indicating that L. plantarum Y44 had the closest evolutionary relationship with these strains. The complete genome of L. plantarum Y44 has been deposited in the NCBI GenBank database under the accession number CP030244-CP030245.
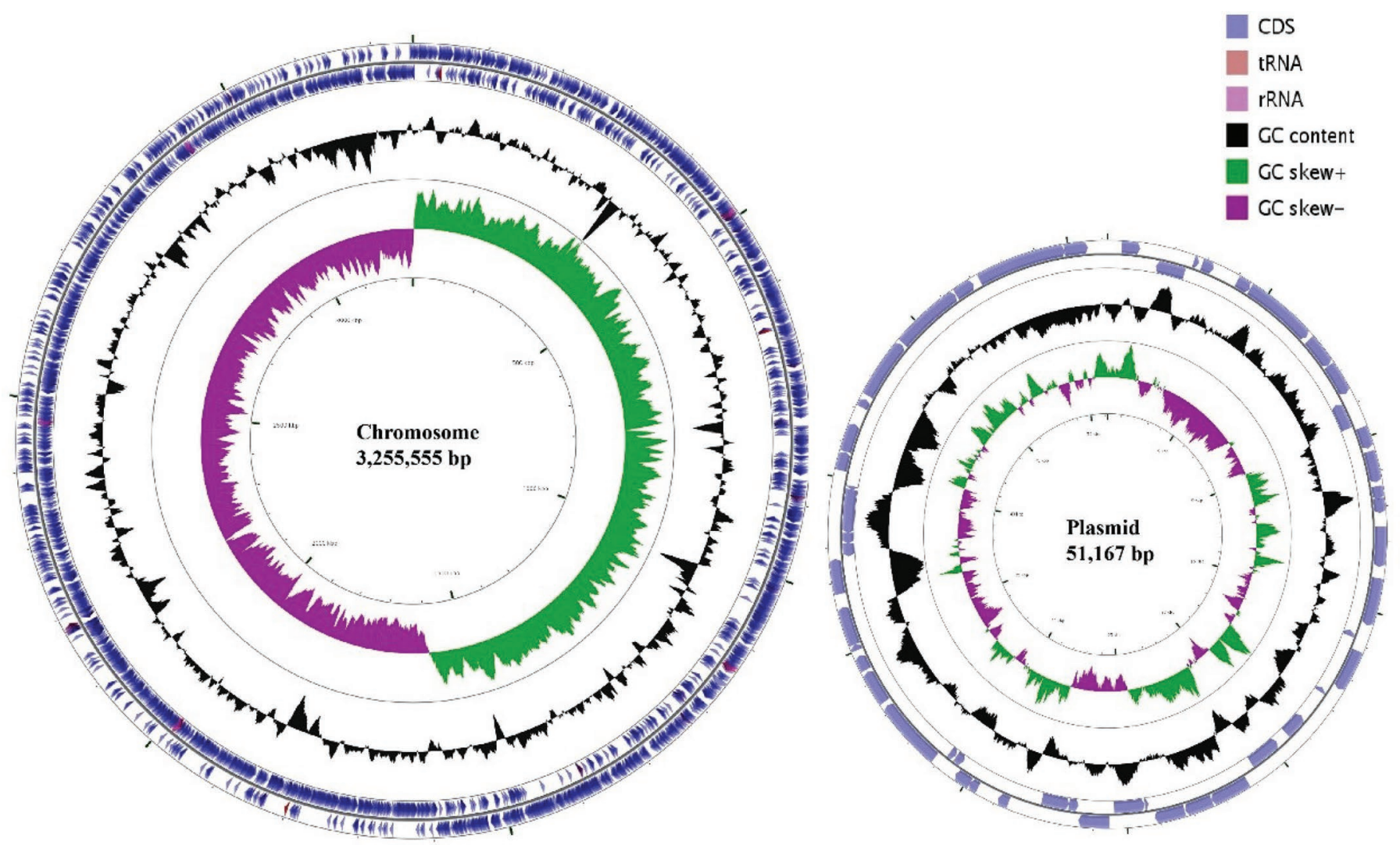

Figure 1. Circular genome maps of Lactobacillus plantarum Y44. For both the chromosome and the plasmid, the first and second circles (starting with the outer circle) illustrate the predicted protein coding sequences (CDS), tRNA, and rRNA on the forward and reverse strands. The third circle represents the $\mathrm{G}+\mathrm{C}$ content of the genome. The fourth circle represents $\mathrm{GC}$ skew $(\mathrm{G}-\mathrm{C}) /(\mathrm{G}+\mathrm{C})$. The fifth circle represents the genome size. 


\section{Carbohydrate Metabolism and Related Genes of L. plantarum Y44}

The carbohydrate utilization profile of $L$. plantarum Y44 was determined with an API 50 CHL kit. As shown in Table 2, L. plantarum Y44 could metabolize 24 kinds of carbohydrate sources. Lactobacillus plantarum Y44 was not capable of fermenting D-raffinose, even though a $\alpha$-galactosidase gene (melA, DQQ11_14885) was identified in its genome. Lactose represents the principal carbohydrate component in dairy niches. Streptococcus thermophilus and L. bulgaricus normally metabolize lactose and release galactose into the surrounding environment, resulting in the accumulation of residual galactose and unfermented lactose in yogurt making (Anbukkarasi et al., 2014). As shown in Table 2, L. plantarum Y44 strongly fermented lactose and galactose, which would solve the problem of residual galactose and lactose in yogurt fermentation. A total of 3 copies of $\beta$-galactosidase genes (DQQ11_14810, DQQ11_14875, DQQ11_14880) were identified in the $L$. plantarum Y44 genome. The Leloir pathway is a crucial lactose metabolism pathway, and genes encoding the complete pathway were identified in the L. plantarum Y44 genome, including UDP-glucose-hexose-1-phosphate gene, galactokinase gene, UDP-glucose 4-epimerase gene, and aldose 1-epimerase gene (Supplemental Table S1; https://doi.org/10.3168/jds.2019-18047). The redundant $\beta$-galactosidase genes, including the Leloir pathway gene, might indicate that $L$. plantarum Y44 possesses better suitability for dairy niches. Beck et al. (2019) found that the carbohydrate utilization profile of different L. plantarum strains could vary, as shown through a comparison of carbohydrate fermentation patterns among L. plantarum ATG-K2, ATG-K6, and ATG-K8 by API50 CHL kit.

Lactobacillus plantarum is a versatile and flexible species that is able to grow on a wide variety of sugar sources. This phenotypic trait is associated with the genes encoding proteins related to carbohydrate transport and metabolism. The majority of transporters are within the phosphoenolpyruvate-dependent sugar phosphotransferase system (PTS). The complete PTS encoded by the $L$. plantarum Y44 genome includes general enzyme I gene (EI, DQQ11_05360), phosphocarrier protein HPr gene (DQQ11_05355), 19 complete substrate-specific enzyme II (EII) complexes genes, and genes for several incomplete complexes (Supplemental Table S2; https://doi.org/10.3168/jds.2019 -18047). In the L. plantarum Y44 genome, the genes for glucose-glucoside (Glc), fructose-mannitol (Fru), mannose-fructose-sorbose (Man), and lactose-N, $\mathrm{N}^{\prime}-$ diacetylchitobiose- $\beta$-glucoside (Lac) family EII complexes were present as multiple copies, while the genes for galactitol (Gat), L-ascorbate (Asc), and glucitol (Gut) family of EII complexes were present as single copies. In addition to those in the PTS system, $L$. plantarum Y44 possessed dozens of other carbohydrate transporters. The substrate specificities of $L$. plantarum Y44 PTS and other carbohydrate transporters could not be predicted. Kleerebezem et al. (2003) explained that some carbohydrate transporter systems are known to import more than one substrate.

Lactobacillus plantarum is grouped among the facultative heterofermentative lactobacilli, which ferment sugars via the Embden-Meyerhof-Parnas (EMP) pathway or the hexose monophosphate (HMP) pathway, leading to homolactic and heterolactic fermentation profiles, respectively (Kleerebezem et al., 2003). Lactobacillus plantarum degraded glucose via the EMP pathway to produce pyruvate, which was subsequently converted into D- and L-lactate by lactate dehydrogenase enzymes (Liu et al., 2015). The genes encoding enzymes involved in the intact EMP and HMP pathways were predicted in the L. plantarum Y44 genome (Supplemental Table S1). Two D-lactate dehydrogenase genes $(l d h D)$ and 5 L-lactate dehydrogenase genes $(l d h L$, Supplemental Table S1) were found in the L. plantarum Y44 genome. Two L-lactate dehydrogenase genes and one D-lactate dehydrogenase gene were identified in the genome of L. plantarum 5-2 (Liu et al., 2015). Lactobacillus plantarum Y44 displayed redundancy in its lactate dehydrogenase-encoding genes, indicating that the strain has a pyruvate-dissipating capacity in fermenta-

Table 1. Genomic information of Lactobacillus plantarum Y44

\begin{tabular}{lccc}
\hline Item & Complete genome & Chromosome & Plasmids \\
\hline Size (bp) & $3,306,722$ & $3,255,555$ & 51,167 \\
GC content (\%) & 44.5 & 44.6 & 38.8 \\
Gene & 3,194 & 3,142 & 52 \\
Protein coding sequence & 3,103 & 2,967 & 46 \\
tRNA & 66 & 66 & - \\
rRNA & 16 & 16 & - \\
Small (s)RNA & 4 & 4 & 6 \\
Pseudo gene & 95 & 10 & - \\
Methylation site & 10 & & \\
\hline
\end{tabular}




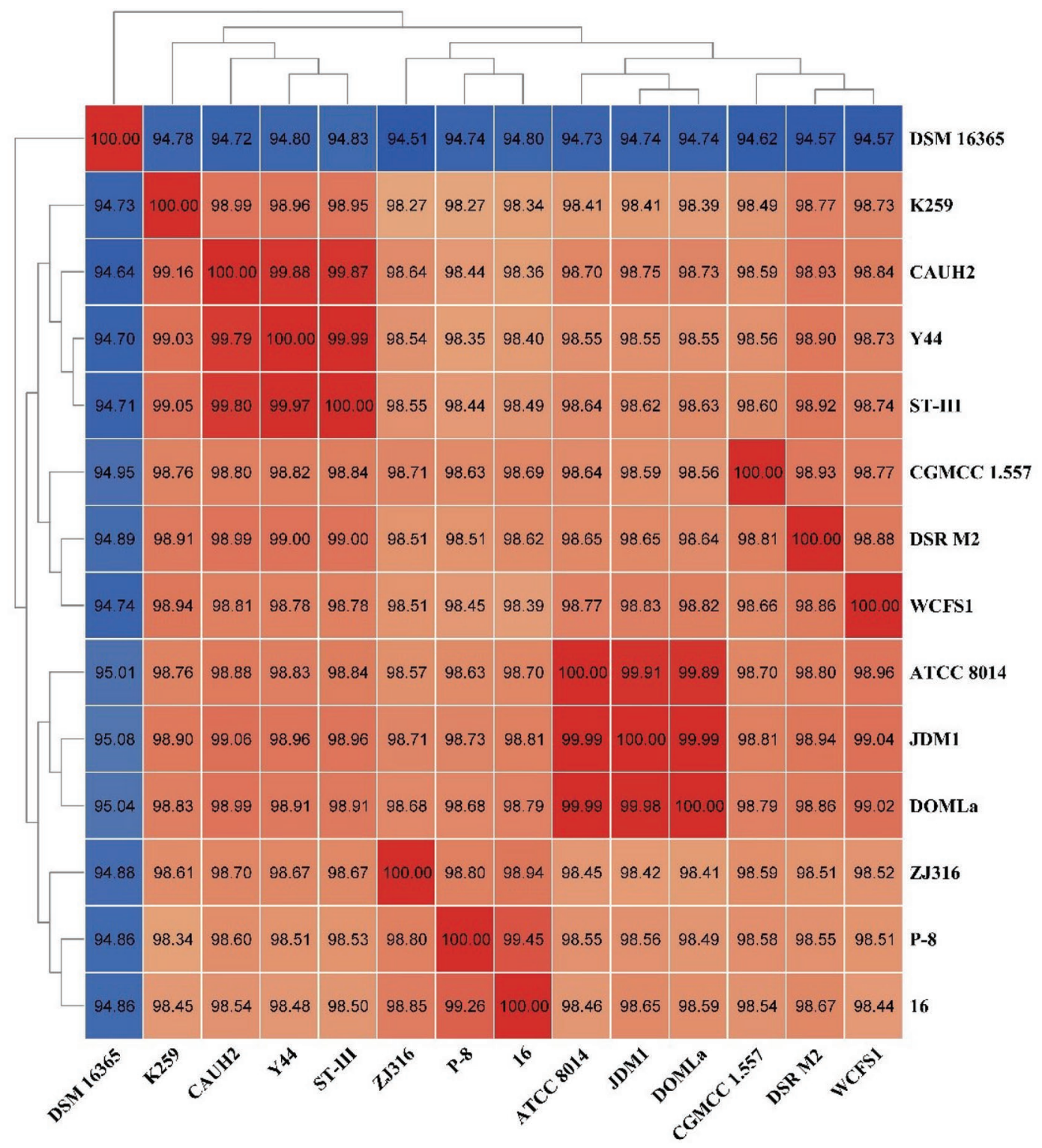

Figure 2. Average nucleotide identity (ANI) values of Lactobacillus plantarum strains. The numbers indicate the ANI of each L. plantarum strain.

tion. Aside from the lactate dehydrogenase genes, the L. plantarum Y44 genome contains a relatively large number of other pyruvate-dissipating enzymes, which are predicted to catalyze the production of other metabolites, including formate, acetate, ethanol, acetoin, oxaloacetate, and acetyl-CoA (Supplemental Table S1). Formate, acetate, ethanol, acetoin, and oxaloacetate are important flavor compounds of fermented milk or cheese (Marshall, 1987). The L. plantarum Y44 genome did not encode proteins related to the intact citrate acid cycle (tricarboxylic acid cycle), but some genes in this pathway were present (Supplemental Table S1). It was previously reported that the genomes of L. planta- rum 5-2 (Liu et al., 2015) and L. plantarum ZJ316 (Li et al., 2016) also did not encode an intact TCA cycle.

The analysis of carbohydrate active enzyme genes using the CAZy database showed that the L. plantarum Y44 genome contains 203 genes in the 5 CAZymes gene families as follows: 28 auxiliary activity genes, 18 carbohydrate-binding module genes, 30 carbohydrate esterase genes, 75 glycoside hydrolase genes, and 52 glycosyl transferase genes. These numbers of carbohydrate active enzyme genes were relatively larger than those found for L. plantarum KLDS1.0391 and L. plantarum ZLP001, which harbored 119 genes and 94 genes, respectively (Zhang et al., 2018; Jia et al., 
2017a). However, the carbohydrate utilization capacity of L. plantarum KLDS1.0391 and L. plantarum ZLP001 are unknown.

\section{Genes Related to Proteolysis and Amino Acid Metabolism in L. plantarum Y44}

Dairy microbes have abundant proteolytic and amino acid metabolism genes that enable uptake of nutrients present in the dairy environment (Stefanovic and McAuliffe, 2018). Lactobacillus strains are generally equipped with protein-degradation machinery to create a selective advantage for growth. Unlike other Lactobacillus strains, L. plantarum did not appear to contain a gene encoding the extracellular protease Prt, which is involved in primary breakdown of proteins (Kleerebezem et al., 2003). As for the L. plantarum Y44 genome, it did not encode extracellular protease Prt. The L. plantarum genome encoded peptide uptake systems for transporting oligopeptides into the cells as nitrogen sources. Oligopeptide and di-/tripeptide (DtpT) uptake systems are major peptide uptake systems in L. plantarum (Kleerebezem et al., 2003). We found that the L. plantarum Y44 genome contained intact opp peptide uptake system genes, including opp operon (oppA-oppF), and 7 redundant copies of oppA genes (Supplemental Table S3; https://doi.org/10 .3168/jds.2019-18047). Furthermore, L. plantarum Y44 contained a gene encoding the $d t p T$ peptide uptake system, which could transport DtpT (Supplemental Table S3). Lactobacillus plantarum Y44 contained 19 genes encoding intracellular peptidases, such as aminopeptidase, endopeptidase, proline-specific peptidase, dipeptidase, and tripeptidase (Supplemental Table S3). Milk is relatively poor in free amino acids, and peptidases provide a selective advantage for bacteria growing in this medium (Bolotin et al., 2001).

Amino acid catabolism has an impact on fermentation regulation and on the flavor of dairy products. Similar to other L. plantarum strains, the L. plantarum Y44 genome encodes complete pathways for the biosynthesis of most amino acids, other than the branchedchain amino acids valine, leucine, and isoleucine. The capability for amino acid biosynthesis supports $L$. plantarum Y44 growth and survival in environments deficient in amino acids. A total of 13 amino acid aminotransferase genes were identified in the genome of $L$. plantarum Y44 (Supplemental Table S3). Amino acids can be converted into their corresponding $\alpha$-keto acids via catalysis by aminotransferase (Liu et al., 2008). The $\alpha$-keto acids are subsequently converted into aldehydes, alcohols, and esters, which are important aroma compounds in dairy products.
Table 2. Carbohydrate fermentation patterns of Lactobacillus plantarum $\mathrm{Y} 44^{1}$

\begin{tabular}{|c|c|c|}
\hline \multirow[b]{2}{*}{ Sugar } & \multicolumn{2}{|c|}{ Strain $^{2}$} \\
\hline & Y44 & ATCC14917 \\
\hline Control & - & - \\
\hline Glycerol & - & - \\
\hline Erythritol & - & - \\
\hline D-Arabinose & - & - \\
\hline L-Arabinose & + & + \\
\hline D-Ribose & + & + \\
\hline D-Xylose & - & - \\
\hline L-Xylose & - & - \\
\hline Adonitol & - & - \\
\hline Methyl- $\beta$ D-xylopyranoside & - & - \\
\hline D-Galactose & + & + \\
\hline D-Glucose & + & + \\
\hline D-Fructose & + & + \\
\hline D-Mannose & + & + \\
\hline D-Sorbose & - & - \\
\hline D-Rhamnose & - & - \\
\hline Dulcitol & - & - \\
\hline Inositol & - & - \\
\hline D-Mannitol & + & + \\
\hline D-Sorbitol & + & + \\
\hline Methyl- $\alpha$ D-mannopyranoside & + & + \\
\hline Methyl- $\alpha$ D-glucopyranoside & - & - \\
\hline N-Acetylglucosamine & + & + \\
\hline Amygdalin & + & + \\
\hline Arbutin & + & + \\
\hline Esculin ferric citrate & + & + \\
\hline Salicin & + & + \\
\hline D-Cellobiose & + & + \\
\hline D-Maltose & + & + \\
\hline D-Lactose & + & + \\
\hline D-Melibiose & + & + \\
\hline D-Sucrose & + & + \\
\hline D-Trehalose & + & + \\
\hline Inulin & - & - \\
\hline D-Melezitose & + & + \\
\hline D-Raffinose & - & + \\
\hline Starch & - & - \\
\hline Glycogen & - & - \\
\hline Xylitol & - & - \\
\hline Gentiobiose & + & + \\
\hline D-Turanose & + & + \\
\hline D-Lyxose & - & - \\
\hline D-Tagatose & - & - \\
\hline D-Fucose & - & - \\
\hline L-Fucose & - & - \\
\hline D-Arabitol & - & - \\
\hline L-Arabitol & - & - \\
\hline Gluconate & + & + \\
\hline 2-Keto-gluconate & - & - \\
\hline 5-Keto-gluconate & - & - \\
\hline
\end{tabular}

${ }^{1}$ Fermentation results are indicated as follows: +, positive; - , negative. ${ }^{2} \mathrm{Y} 44=$ L. plantarum $\mathrm{Y} 44 ;$ ATCC14917 $=$ L. plantarum ATCC14917.

\section{Capacity for Adhesion to HT-29 Cell Monolayers and Adhesion Factors of L. plantarum Y44}

Adhesion of L. plantarum Y44 to HT-29 cell monolayers is shown in Figure 3, with L. rhamnosus GG as a positive control. Lactobacillus plantarum Y44 exhibited the same capacity for adhesion to HT-29 cell monolay- 
ers as L. rhamnosus GG $(P>0.05)$. When L. plantarum Y44 and L. rhamnosus GG were treated with $\mathrm{LiCl}$ to partially remove cell surface proteins, the cell viability of L. plantarum Y44 was decreased to $50 \%$. We then adjusted the concentration of living $L$. plantarum Y44 to $5 \times 10^{8} \mathrm{cfu} / \mathrm{mL}$ after $\mathrm{LiCl}$ treatment to match the concentration of untreated L. plantarum Y44. Adhesion of LiCl-treated L. plantarum Y44 to HT-29 cells was significantly lower than that of untreated L. plantarum Y44 $(P<0.05)$, indicating that surface proteins might account for the adhesion capacity of L. plantarum Y44. Previous studies demonstrated that the ability of some Lactobacillus strains to adhere to the intestinal mucosa is attributable to their cell surface proteins (Monteagudo-Mera et al., 2019; Meng et al., 2014). These reports are in accordance with our result that the adhesion capacity of L. plantarum Y44 was reduced by removing cell surface proteins.

Monteagudo-Mera et al. (2019) inferred that cell surface proteins might work as adhesion mediators when lactobacilli adhere to intestinal epithelial cells. Lactobacillus plantarum Y44 contains genes encoding extracellular proteins such as LPxTG-type anchors protein, LysM domains protein, and $\mathrm{WxL}$ domain protein (Supplemental Table S4; https://doi.org/10.3168/ jds.2019-18047). These proteins might play a role in adhesion or binding to other cells or proteins, because they contain mucus-binding, fibronectin-binding, aggregation-promoting, intercellular adhesion, or cell clumping domains that are involved in cell-envelope binding

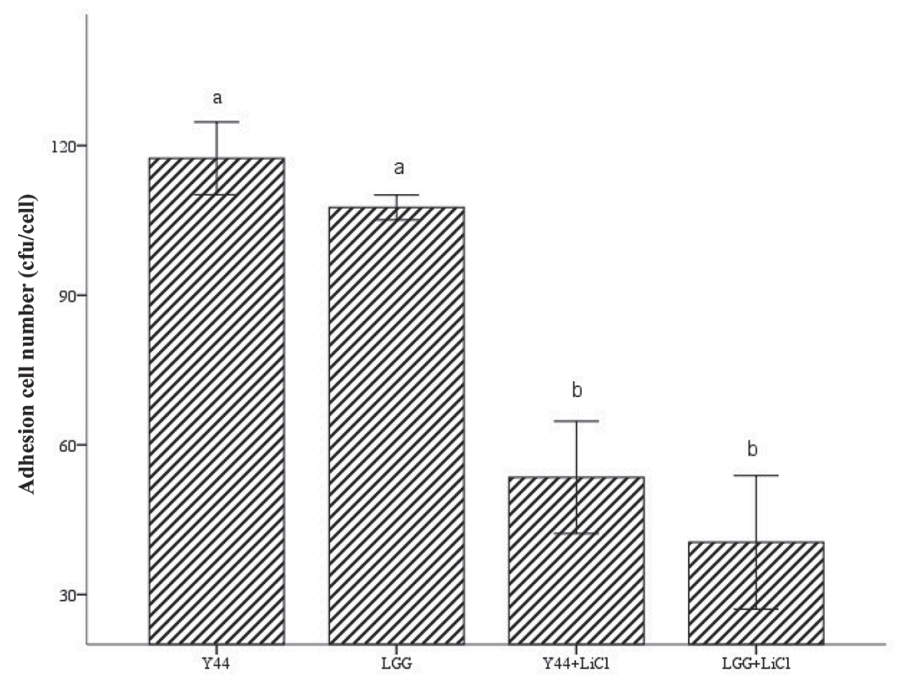

Figure 3. The adhesion capacity of Lactobacillus plantarum Y44 to HT-29 cells. Y44 $=$ L. plantarum Y44; LGG $=$ Lactobacillus rhamnosus $\mathrm{GG}$. The results are expressed as means $\pm \mathrm{SD}(\mathrm{n}=3)$. Different lowercase letters ( $a$ and $b$ ) on columns indicate a significant difference in the number of adhered bacterial cells per HT-29 cell between different Lactobacillus strains at the 0.05 level. The same letter indicates no significant difference at the 0.05 level.
(Kleerebezem et al., 2003). Lactobacillus plantarum Y44 also contained 2 mucus-binding protein genes and a fibronectin/fibrinogen-binding protein gene (Supplemental Table S4). A previous study demonstrated that these 2 kinds of proteins play an important role in adhesion and colonization of intestinal mucosal surfaces or fibronectin (Altermann et al., 2005).

Exopolysaccharide (EPS) is a high molecular weight carbohydrate polymer secreted by many microorganisms, and it generally plays a role in the nonspecific interactions of lactobacilli with epithelial cells (AlDhaheri et al., 2017). The EPS-producing cultures used as starters or adjuncts in making yogurt and cheese can positively influence product characteristics such as viscosity and syneresis for yogurt and moisture and firmness for cheese (Che et al., 2019). In our previous study, EPS of L. plantarum Y44 was composed of mannose, glucuronic acid, glucosamine, glucose, and galactose, and it exhibited antioxidant activity (Liu et al., 2019). The biosynthesis of EPS involves sugar uptake, nucleotide sugar synthesis, and polysaccharide synthesis and export (Xiong et al., 2019). Predicted pathways of sugar uptake and nucleotide sugar synthesis of L. plantarum Y44 are shown in Figure 4A. Various sugar sources are transported intracellularly by corresponding transporters and then metabolized to their corresponding nucleotide sugars, such as GDP-D-mannose, UDP-N-acetyl$\alpha$-D-glucosamine, UDP-glucose, UDP-galactose, and UDP-glucuronate, as previously reported (Cui et al., 2017). However, the genotype and phenotype did not completely coincide in our study. For example, the corresponding coding genes for these enzymes, including those responsible for the catalytic formation of GDP-Dmannose from mannose-6-P and the catalytic formation of UDP-glucuronate from UDP-glucose, were not found in the genome of L. plantarum Y44 via in silico KEGG pathway analysis. The predicted EPS synthesis gene cluster of L. plantarum Y44 is shown in Figure 4B and Supplemental Table S5 (https://doi.org/10.3168/jds .2019-18047). Compared with L. plantarum WCFS1, L. plantarum Y44 did not contain genes encoding the cps1 cluster. In addition, the cps2 gene clusters of Lactobacillus plantarum strains were diverse; cps2FGHI genes of L. plantarum Y44 had low homology with those of L. plantarum WCFS1, whereas the cps2FGHI genes of L. plantarum Y44 were highly homologous with the cps $4 F G H I$ genes of $L$. plantarum WCFS1. Lee et al. (2016a) found that the first 5 genes (cps2ABCDE) in the cps2 gene cluster of L. plantarum Lp90 and L. plantarum SF2A35B were highly homologous to those of L. plantarum WCFS1, and the remaining genes in the cps2 gene cluster were unique. The cps3 and cps4 gene clusters were highly homologous between $L$. plantarum Y44 and L. plantarum WCFS1. Jiang and Yang (2018) 
reported that the cps gene clusters of 43 L. plantarum strains varied considerably mainly because the stains fitted different circumstances.

\section{Genes Encoding Stress-Related Proteins of L. plantarum Y44}

Lactobacillus strains often encounter adverse conditions during fermentation, such as acid stress and oxi- dative stress. In addition, a prerequisite for probiotics is their ability to survive passage through the human gastrointestinal tract, before exerting probiotic effects in the colon (Baccouri et al., 2019). Lactobacillus plantarum Y44 demonstrated favorable transit tolerance and oxidative stress tolerance in our previous studies (Mu et al., 2018, 2019). This phenotypic trait is attributable to the high number of genes encoding proteins involved in stress response. The L . plantarum Y44

(A)

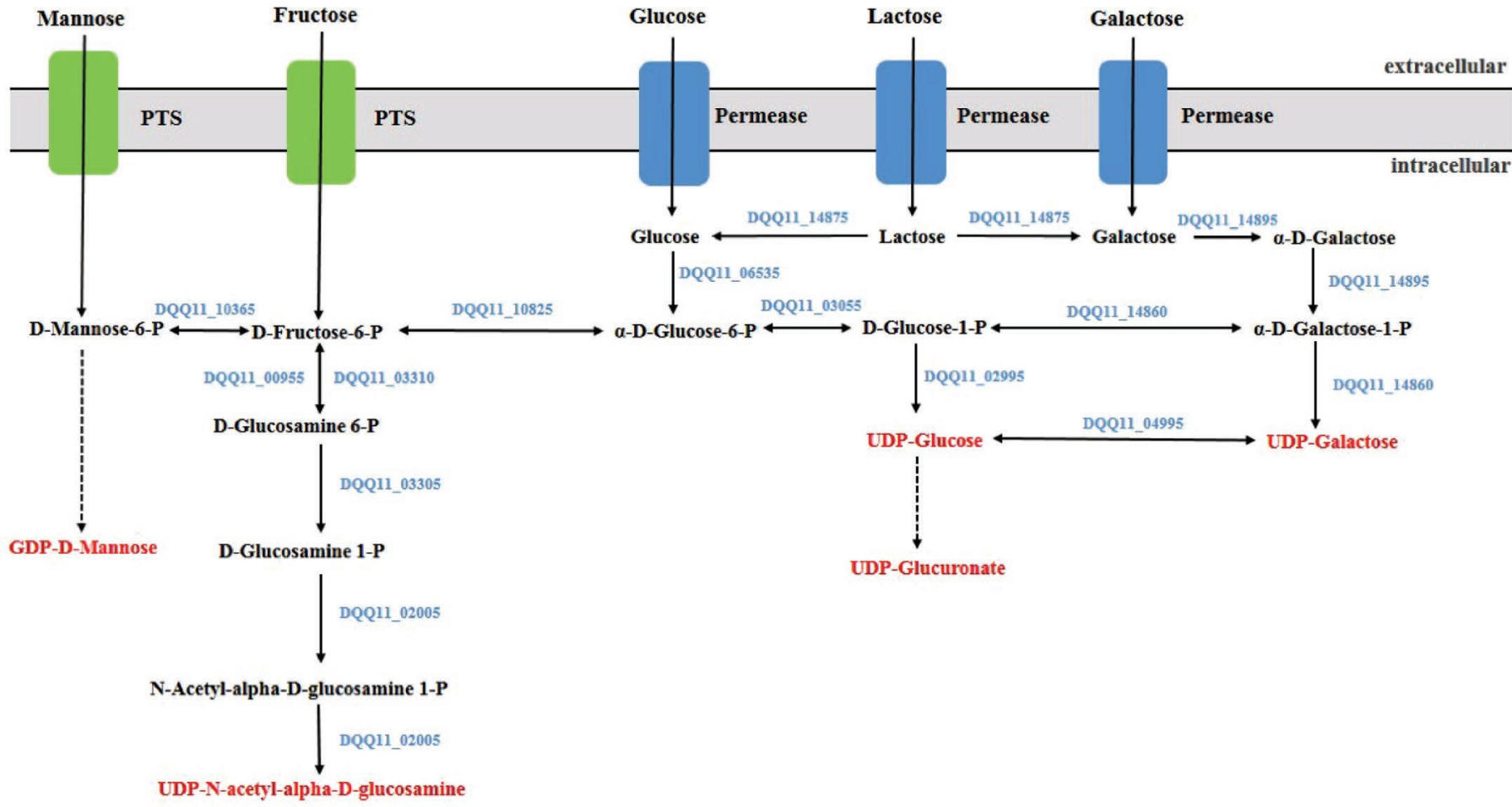

(B)

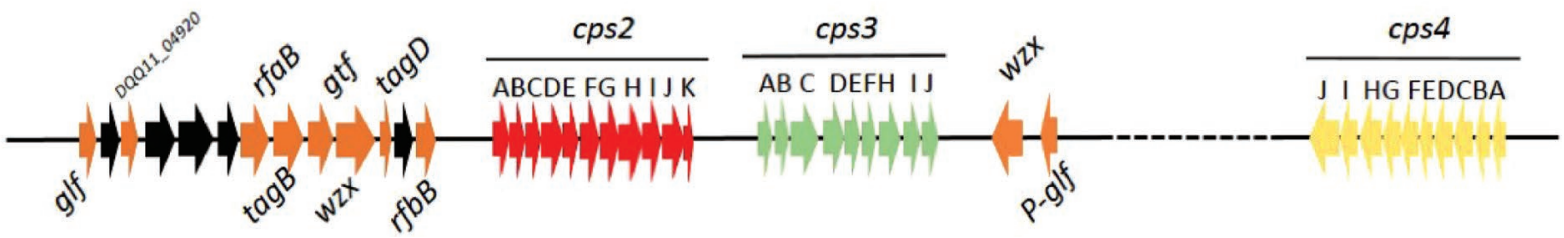

Figure 4. Genes of sugar metabolism for exopolysaccharide (EPS) biosynthesis of Lactobacillus plantarum Y44. (A) Pathways of nucleotide sugar synthesis, where locus tags (DQQ11_...) refer to the enzymes involved in the pathways, dotted arrows correspond to enzymatic reactions from inactive pathways, and red lettering represents nucleotide sugars. (B) The EPS gene cluster of L. plantarum Y44. Arrows with different colors represent genes belonging to different EPS biosynthesis gene clusters of L. plantarum Y44, with red representing genes that belong to the cps2 cluster, green representing genes that belong to the cps3 cluster, yellow representing genes that belong to the cps 4 cluster, orange representing other genes related to EPS biosynthesis, and black representing hypothetical protein. PTS $=$ phosphotransferase system; GDP $=$ guanine diphosphate; UDP = uridine diphosphate. 
genome contained several genes encoding stress-related proteins, as listed in Supplemental Tables S6 and S7 (https://doi.org/10.3168/jds.2019-18047).

Genes encoding chaperones and intracellular proteases were identified in the genome of L. plantarum Y44, including groES-groEL chaperone operons, hrcA-grpE$d n a K$-dnaJ chaperone operons, and the protease-encoding genes $h s l U, h s l V$, lon, clpc, $c l p L, c l p P, c l p E, c l p B$, and $\operatorname{clp} X$ (Supplemental Table S6). Chaperones and proteases are helpful for preventing newly synthesized polypeptide chains and assembled subunits from aggregating and misfolding into nonfunctional structures under a stress condition (Lv et al., 2017). Two-component systems (TCS) act as stimulus-response coupling systems in bacteria (Zschiedrich et al., 2016). At least 14 TCS pairs belonging to 6 families were identified in the genome of L. plantarum Y44 (Supplemental Table S7). Lactococcus lactis ssp. cremoris MG1363 TCS mutants were previously reported to be susceptible to extreme $\mathrm{pH}$, osmotic, or oxidative conditions and to the regulation of phosphatase activity (O'Connell-Motherway et al., 2000). The VicR-VicK system and PhoR-PhoB system were verified to play key roles in regulating stress responses (Deng et al., 2007; Crépin et al., 2011).

In addition to other general stresses, lactic acidproducing bacteria must efficiently deal with the acidification of their local environment (Kleerebezem et al., 2003). As reported in our previous study, the survival rate of $L$. plantarum Y44 in simulated gastric juice for $3 \mathrm{~h}$ was $86.01 \%$, indicating that L. plantarum Y44 possesses favorable acid tolerance (Mu et al., 2018). The $\mathrm{F}_{0} \mathrm{~F}_{1}$-ATPase gene, $\mathrm{Na}^{+} / \mathrm{H}^{+}$-antiporter gene, and $\mathrm{H}^{+} /$ $\mathrm{Cl}^{-}$exchange transporter gene were identified in the genome of L. plantarum Y44, and they were presumed to serve as major regulators of intracellular $\mathrm{pH}$ to allow bacteria to survive in acidic environments (Kleerebezem et al., 2003; Iyer et al., 2002). Similar acid-resistance mechanisms were also found in L. amylolyticus L6 by complete genome sequence analysis (Fei et al., 2018).

Additionally, the survival rate of $L$. plantarum Y44 in simulated intestinal fluid for $8 \mathrm{~h}$ was $85.53 \%(\mathrm{Mu}$ et al., 2018). Cyclopropane-fatty acyl-phospholipid (CFP) synthase, alkaline shock protein, and BSH were regarded as key proteins for protecting Lactobacillus stains against alkaline or bile stress (Hamon et al., 2011; Koskenniemi et al., 2011). Two copies of alkaline shock protein genes were identified in the L. plantarum Y44 genome, and they were expected to play a role in $\mathrm{pH}$ tolerance (Koskenniemi et al., 2011). In addition, the gene encoding CFP synthase was present in the genome of L. plantarum Y44 (Supplemental Table S6); this enzyme was previous reported to be the major regulator for maintaining the integrity of the cell enve- lope and homeostasis against bile salt stress (Hamon et al., 2011; Müller et al., 2014).

Bile salt hydrolases are enzymes that hydrolyze the amide bond of conjugated bile salts, liberating the amino acid moiety from the steroid core and generating deconjugated bile salts (Allain et al., 2018). The BSH activity of L. plantarum Y44 was determined by qualitative and quantitative methods. As shown in Figure $5 \mathrm{~A}$, a white precipitate of deoxycholate in the vicinity of L. plantarum Y44 bacterial colonies appeared due to deconjugation of TDCA and GDCA, respectively, indicating that L. plantarum Y44 possessed BSH activity. With TDCA and GDCA as substrates, the BSH activities of $L$. plantarum Y44 were 0.81 and $1.25 \mathrm{U} /$ $\mathrm{mL}$, respectively, with no significant difference $(P>$ 0.05) compared with those of L. rhamnosus GG, as shown in Figure 5B. Lactobacillus plantarum Y44 and L. rhamnosus GG exhibited the same BSH activities with different substrates. The L. plantarum Y44 genome contained 4 bsh genes, which were predicted to be highly homologous to the genes of $L$. plantarum WCFS1 and L. plantarum ST-III. Four BSH genes were previously identified in the genomes of $L$. plantarum WCFS1 and L. plantarum ST-III, with the bsh1 gene being responsible for the major bile salt hydrolysis activity (Lambert et al., 2008; Ren et al., 2011).

Lactic acid bacteria are anaerobic or facultative anaerobic microorganisms that often encounter oxidative stress during fermentation. Odamaki et al. (2011) found that co-cultivating LAB that had ROS-scavenging ability improved the survival of Bifidobacterium in fermented milk. Our previous studies demonstrated that L. plantarum Y44 can scavenge extracellular ROS, inhibit the production of intracellular ROS, and activate the Nrf-2/Keap-1/ARE signaling pathway of Caco-2 cells (Mu et al., 2018, 2019). We also found that the SOD and GPx activities of L. plantarum Y44 were 16.37 and $17.78 \mathrm{U} / \mathrm{mg}$ of protein, respectively. Superoxide dismutase and GPx are key enzymes in the defense against the adverse effects of ROS in living organisms (Wen et al., 2016). We identified genes encoding proteins or enzymes related to scavenging ROS in the $L$. plantarum Y44 genome, including catalase and peroxidase genes (Supplemental Table S6). These enzymes neutralize hydrogen peroxide to nontoxic water (Zhang et al., 2018). Complete NADH system genes, including $5 \mathrm{NADH}$ oxidase genes and $2 \mathrm{NADH}$ peroxidase genes, were identified in the L. plantarum Y44 genome (Supplemental Table S6). NADH oxidase cooperating with NADH peroxidase can directly quench hydrogen peroxide and enable ROS degradation (Jänsch et al., 2011; Kang et al., 2013). In addition, we found that the L. plantarum Y44 genome contains genes encoding the 
(A)
TDCA
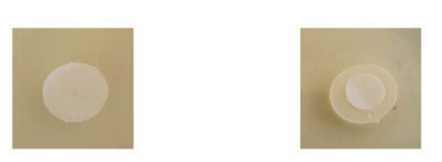

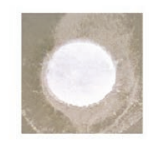

MRS

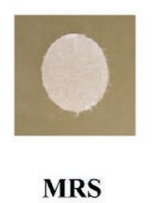

L. plantarum Y44
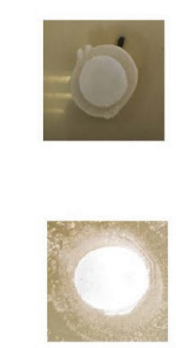

L. rhamnosus GG
(B)

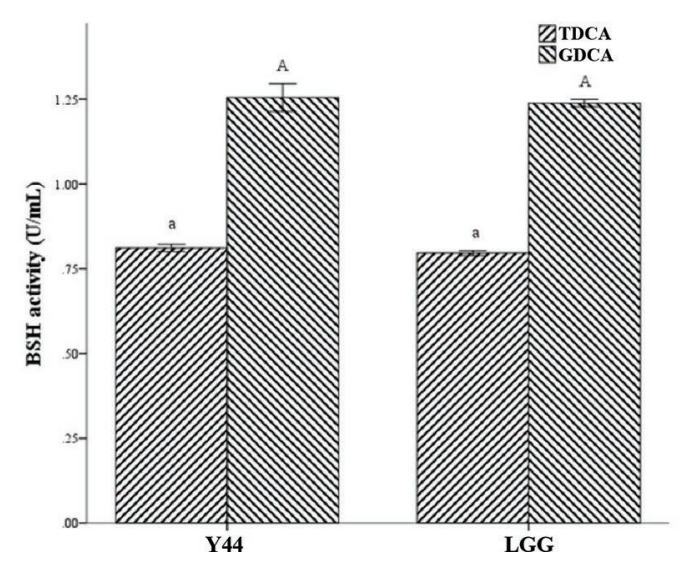

Figure 5. Bile salt hydrolase (BSH) activity of Lactobacillus plantarum Y44 by (A) de Man, Rogosa, and Sharpe agar plate determination, and (B) quantitative determination. The results are expressed as means $\pm \mathrm{SD}(\mathrm{n}=3)$. Different lowercase letters $(\mathrm{a}$ and $\mathrm{b})$ on columns indicate a significant difference at the 0.05 level in taurodeoxycholic acid (TDCA) substrate; different uppercase letters (A and B) on columns indicate a significant difference at the 0.05 level in the glycodeoxycholic acid (GDCA) substrate. The same letter indicates no significant difference at the 0.05 level.

complete glutathione (GSH) system. The predicted genes encoding the GSH system of L. plantarum Y44 included the GSH biosynthesis bifunctional protein gene, GSH peroxidase gene, and GSH reductase gene (Supplemental Table S6). The GSH system detoxifies hydrogen peroxide and lipid peroxyl radicals by regulating the protein dithiol/disulfide balance (Zhang et al., 2018). The thioredoxin system and glutaredoxin catalyze GSH-dependent disulfide reductions to remove ROS at high reaction rates, with glutaredoxin having a thioredoxin-like activity profile (Jordan et al., 1997; Arnér and Holmgren, 2000). The L. plantarum Y44 genome harbored the genes encoding the complete thioredoxin system and glutaredoxin, including 5 thioredoxin genes, 1 thioredoxin reductase gene, 1 thiol peroxidase gene, and 1 glutaredoxin gene (Supplemental Table S6). Lactobacillus plantarum Y44 possesses SOD activity; however, the SOD encoding gene was not found in its genome. Lactobacillus plantarum compensates for the lack of SOD with a high intracellular accumulation of $\mathrm{Mn}^{2+}$, which can scavenge oxygen radicals (Kleerebezem et al., 2003). We found that the L. plantarum Y44 genome contained genes encoding a $\mathrm{Mn}^{2+}$ accumulation system, including P-type manganese translocating ATPase gene, $m t s$ operon ( $m t s A B C$ ), and $m n t H$ family transporter genes (Supplemental Table S6). This $\mathrm{Mn}^{2+}$ accumulation system can regulate transportation and accumulation of $\mathrm{Mn}$, as well as strengthen $L$. plantarum tolerance to oxidative stress (Kleerebezem et al., 2003).

\section{Antibiotic Susceptibility and Antibiotic Resistance Genes of L. plantarum Y44}

Antibiotic susceptibility of L. plantarum Y44 was assessed according to the recommendations of the EFSA. Lactobacillus plantarum Y44 exhibited antibiotic susceptibility within the recommended cut-off values as shown in Table 3. The results from CARD database searching showed that L. plantarum Y44 did not contain strict or perfect antibiotic resistance genes (Figure 6A). However, the results from Resfams database searching identified more than 30 vancomycin resistance genes in the L. plantarum Y44 genome (Figure 6B). Although the EFSA guideline does not require vancomycin susceptibility of $L$. plantarum, MIC of vancomycin for $L$. plantarum Y44 was more than $128 \mu \mathrm{g} / \mathrm{mL}$. This finding was consistent with previous research showing that Lactobacillus strains exhibited resistance to vancomycin (Ammor et al., 2007; Liu et al., 2009).

Lactobacillus, Pediococcus, and Leuconostoc species were reported to be resistant to vancomycin due to their possession of D-Ala-D-lactate in their peptidoglycan rather than the D-Ala-D-Ala dipeptide (Ammor et al., 2007). According to EFSA FEEDAP Panel et al. (2018), bacteria used as probiotics for humans or as additives for animal feed should not carry transferable antimicrobial resistance genes. The results from ResFinder showed that L. plantarum Y44 does not carry any acquired antibiotic resistance genes, indicating that the vancomycin resistance genes of L. plantarum Y44 were intrinsic rather than acquired by horizontal genomic transfer. Zhang et al. (2012) reported that the intrinsic type of antibiotic resistance of lactobacilli is not a particular safety concern.

\section{Biogenic Amine Production}

Biogenic amines compose a group of low-molecularweight nitrogenous compounds that are produced through microbial amino acid decarboxylation (Capozzi et al., 2012). Dairy products, in particular cheese, can accumulate high levels of biogenic amines, mainly 
Table 3. Antibiotic susceptibility of Lactobacillus plantarum Y44

\begin{tabular}{lccc}
\hline Antibiotic & MIC $^{1}(\mu \mathrm{g} / \mathrm{mL})$ & Cut-off value $^{2}(\mu \mathrm{g} / \mathrm{mL})$ & Susceptibility $^{1}$ \\
\hline Gentamicin & 2 & 16 & $\mathrm{~S}$ \\
Kanamycin & 64 & 64 & $\mathrm{~S}$ \\
Tetracycline & 16 & 32 & $\mathrm{~S}$ \\
Clindamycin & 2 & 2 & $\mathrm{~S}$ \\
Ampicillin & 2 & 2 & $\mathrm{~S}$ \\
Erythromycin & 0.25 & 1 & $\mathrm{~S}$ \\
Chloramphenicol & 4 & 8 & $\mathrm{~S}$ \\
Vancomycin & $\mathrm{NR}$ & $\mathrm{NR}$ \\
${ }^{1}$ NR = not reported; S = susceptible. & \\
${ }^{2}$ Cut-off value was based on European Food Safety Authority (EFSA) recommendations.
\end{tabular}

histamine and tyramine, which are known to be toxic (Ladero et al., 2012). Control of biogenic amines to be within the safety level is critical for the safety assessment of probiotics (Li et al., 2018). As shown in Figure 7 , the decarboxylase medium plate inoculated with $L$. plantarum Y44 did not show a purple color, indicating that the strain did not produce biogenic amine. The genome sequencing results showed that L. plantarum Y44 has only one amino acid decarboxylase gene, glutamate decarboxylase (DQQ11_14585). Zhang et al. (2012) reported that the L. plantarum JDM1 genome contained glutamate decarboxylase, but the strain did not produce biogenic amine. Glutamate decarboxylase catalyzes $\alpha$-decarboxylation of L-glutamate to produce 4-aminobutanoate ( $\gamma$-aminobutyric acid), which was not involved in producing biogenic amines (Huang et al., 2018). The genotype of L. plantarum Y44 could

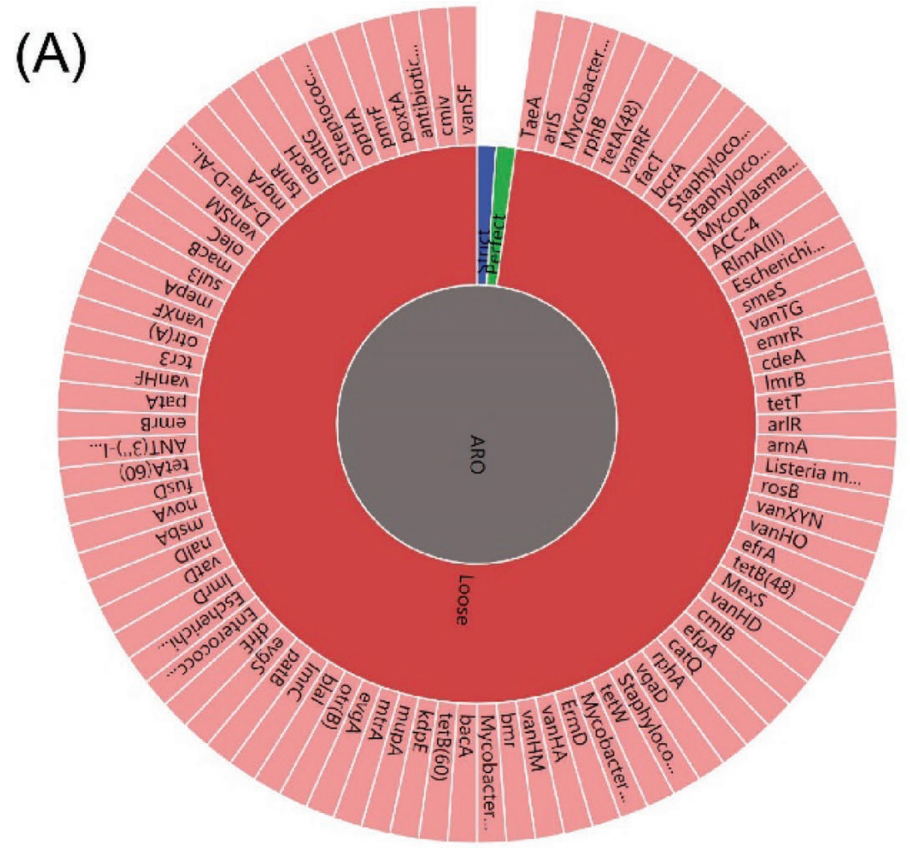

account for its phenotypic characteristic of not producing biogenic amines. Hill et al. (2017) recommended that preselection of starter cultures lacking the amino acid decarboxylase gene may be necessary to avoid unwanted build-up of biogenic amine compounds in fermented foods.

\section{CONCLUSIONS}

In this study, we investigated the physiological functions of L. plantarum Y44 by analyzing its phenotypic and genotypic characteristics. Lactobacillus plantarum Y44 could metabolize 24 different sugars. It also had BSH activity, the capacity to adhere to HT-29 cell monolayers, susceptibility to different antibiotics, no biogenic amine production, and antioxidant enzyme activity. The results of the L. plantarum Y44 genome

(B)

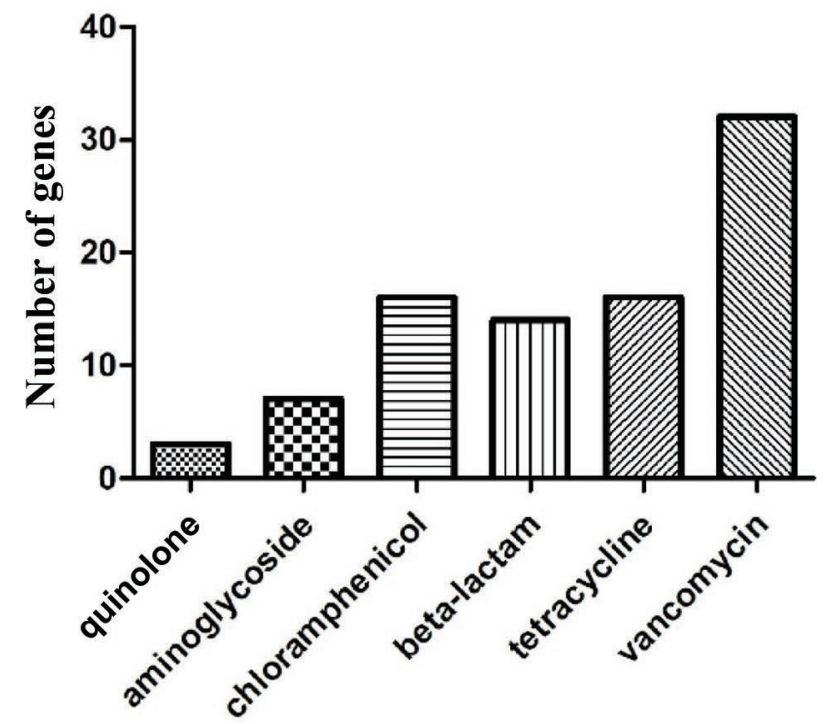

Figure 6. Predicted antibiotic resistance genes of Lactobacillus plantarum Y44: (A) CARD database prediction, and (B) Resfam database prediction. 


\section{Arginine Ornithine Lysine Tryptophan Histidine Phenylalanine Tyrosine
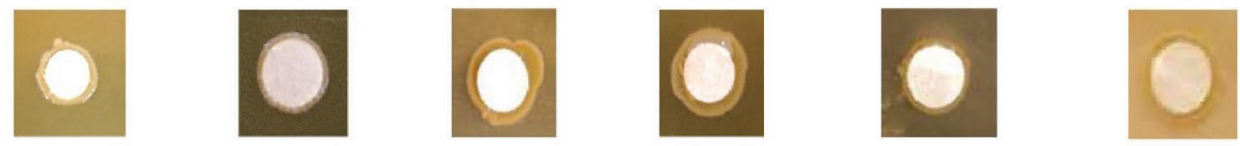 \\ L. rhamnosus GG
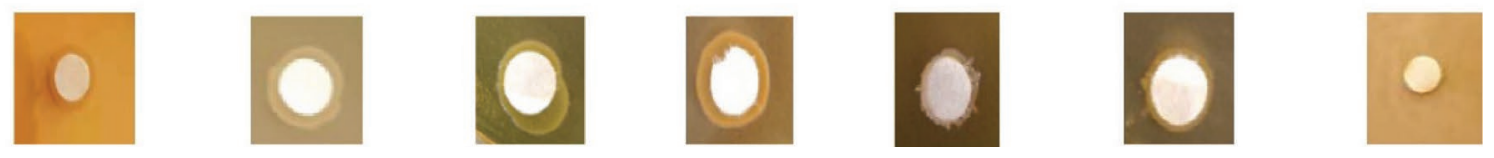

Figure 7. Biogenic amine production of Lactobacillus plantarum Y44 with different precursor amino acids. L. rhamnosus $=$ Lactobacillus rhamnosus.

analysis revealed gene clusters associated with carbohydrate transport and metabolism systems, proteolytic systems, amino acid metabolism, EPS biosynthesis, surface protein biosynthesis, stress response, and antibiotic resistance. The phenotypic characteristics of $L$. plantarum Y44 were associated with its genotypic characteristics. The physiological functions of L. plantarum Y44 - such as tolerance to acid, bile salt, and oxygen; proteolytic capability; and ability to metabolize various carbohydrates and amino acids - form the foundation for its commercial application in dairy products.

\section{ACKNOWLEDGMENTS}

This study was funded by the National Natural Science Foundation of China (No. 31671828) and National Key Research and Development Plan (No. 2018YFC1604102). The authors have stated no conflicts of interest.

\section{REFERENCES}

Al-Dhaheri, A. S., R. Al-Hemeiri, J. Kizhakkayil, A. Al-Nabulsi, A. Abushelaibi, N. P. Shah, and M. Ayyash. 2017. Health-promoting benefits of low-fat akawi cheese made by exopolysaccharideproducing probiotic Lactobacillus plantarum isolated from camel milk. J. Dairy Sci. 100:7771-7779. https://doi.org/10.3168/jds .2017-12761.

Allain, T., S. Chaouch, M. Thomas, I. Vallée, A. G. Buret, P. Langella, P. Grellier, B. Polack, L. Bermúdez-Humarán, and I. Florent. 2018. Bile-salt-hydrolases from the probiotic strain Lactobacillus johnsonii La1 mediate anti-giardial activity in vitro and in vivo. Front. Microbiol. 8:2707. https://doi.org/10.3389/fmicb.2017.02707.

Altermann, E., W. M. Russell, M. A. Azcarate-Peril, R. Barrangou, B. L. Buck, O. McAuliffe, N. Souther, A. Dobson, T. Duong, M. Callanan, S. Lick, A. Hamrick, R. Cano, and T. R. Klaenhammer. 2005. Complete genome sequence of the probiotic lactic acid bacterium Lactobacillus acidophilus NCFM. Proc. Natl. Acad. Sci. USA 102:3906-3912. https://doi.org/10.1073/pnas.0409188102.

Ammor, M. S., A. B. Flórez, and B. Mayo. 2007. Antibiotic resistance in non-enterococcal lactic acid bacteria and bifidobacteria. Food Microbiol. 24:559-570. https://doi.org/10.1016/j.fm.2006.11.001.

Anbukkarasi, K., T. UmaMaheswari, T. Hemalatha, D. K. Nanda, P. Singh, and R. Singh. 2014. Preparation of low galactose yogurt using cultures of Gal+ Streptococcus thermophilus in combination with Lactobacillus delbrueckii ssp. bulgaricus. J. Food Sci. Technol. 51:2183-2189. https://doi.org/10.1007/s13197-014-1262-5.

Aramaki, T., R. Blanc-Mathieu, H. Endo, K. Ohkubo, M. Kanehisa, S. Goto, and H. Ogata. 2019. KofamKOALA: KEGG ortholog assignment based on profile HMM and adaptive score threshold. Bioinformatics btz859. https://doi.org/10.1093/bioinformatics/btz859.

Arnér, E. S., and A. Holmgren. 2000. Physiological functions of thioredoxin and thioredoxin reductase. Eur. J. Biochem. 267:6102-6109. https://doi.org/10.1046/j.1432-1327.2000.01701.x.

Baccouri, O., A. M. Boukerb, L. Ben Farhat, A. Zébré, K. Zimmermann. E. Domann, M. Cambronel, M. Barreau, O. Maillot, I. Rincé, C. Muller, M. N. Marzouki, M. Feuilloley, F. Abidi, and N. Connil. 2019. Probiotic potential and safety evaluation of Enterococcus faecalis OB14 and OB15, isolated from traditional Tunisian Testouri cheese and Rigouta, using physiological and genomic analysis. Front. Microbiol. 10:881. https://doi.org/10.3389/fmicb .2019.00881.

Beck, B. R., G.-S. Park, Y. H. Lee, S. Im, D. Y. Jeong, and J. Kang. 2019. Whole genome analysis of Lactobacillus plantarum strains isolated from kimchi and determination of probiotic properties to treat mucosal infections by Candida albicans and Gardnerella vaginalis. Front. Microbiol. 10:433. https://doi.org/10.3389/fmicb .2019 .00433

Bolotin, A., P. Wincker, S. Mauger, O. Jaillon, K. Malarme, J. Weissenbach, S. K. Ehrlich, and A. Sorokin. 2001. The complete genome sequence of the lactic acid bacterium Lactococcus lactis ssp. lactis IL1403. Genome Res. 11:731-753. https://doi.org/10.1101/ gr.GR-1697R.

Bover-Cid, S., and W. H. Holzapfel. 1999. Improved screening procedure for biogenic amine production by lactic acid bacteria. Int. J. Food Microbiol. 53:33-41. https://doi.org/10.1016/S0168 -1605(99)00152-X.

Capozzi, V., P. Russo, V. Ladero, M. Fernández, D. Fiocco, M. A. Alvarez, F. Grieco, and G. Spano. 2012. Biogenic amines degradation by Lactobacillus plantarum: Toward a potential application in wine. Front. Microbiol. 3:122. https://doi.org/10.3389/fmicb.2012 .00122 .

Chang, M., and H. C. Chang. 2012. Development of a screening method for biogenic amine producing Bacillus spp. Int. J. Food Microbiol. 153:269-274. https://doi.org/10.1016/j.ijfoodmicro.2011 .11 .008 .

Che, H., H. Zhang, Y. Tian, P. F. Lai, Y. Xia, S. Wang, and L. Ai. 2019. Exopolysaccharide from Streptococcus thermophilus as stabilizer in fermented dairy: Binding kinetics and interactions with casein of milk. Int. J. Biol. Macromol. 140:1018-1025. https://doi .org/10.1016/j.ijbiomac.2019.08.146.

Chin, C.-S., D. H. Alexander, P. Marks, A. A. Klammer, J. Drake, C. Heiner, A. Clum, A. Copeland, J. Huddleston, E. E. Eichler, S. W. Turner, and J. Korlach. 2013. Nonhybrid, finished microbial 
genome assemblies from long-read SMRT sequencing data. Nat. Methods 10:563-569. https://doi.org/10.1038/nmeth.2474.

Crépin, S., S. M. Chekabab, G. Le Bihan, N. Bertrand, C. M. Dozois, and J. Harel. 2011. The Pho regulon and the pathogenesis of Escherichia coli. Vet. Microbiol. 153:82-88. https://doi.org/10.1016/j vetmic.2011.05.043.

Cui, Y., X. Jiang, M. Hao, X. Qu, and T. Hu. 2017. New advances in exopolysaccharides production of Streptococcus thermophilus. Arch. Microbiol. 199:799-809. https://doi.org/10.1007/s00203-017 -1366-1.

Deng, D. M., M. J. Liu, J. M. Ten Cate, and W. Crielaard. 2007. The VicRK system of Streptococcus mutans responds to oxidative stress. J. Dent. Res. 86:606-610. https://doi.org/10.1177/ 154405910708600705.

EFSA FEEDAP Panel, G. Rychen, G. Aquilina, G. Azimonti, V. Bampidis, M. L. Bastos, G. Bories, A. Chesson, P. S. Cocconcelli, G. Flachowsky, J. Gropp, B. Kolar, M. Kouba, M. Lopez-Alonso, S. Lopez Puente, A. Mantovani, B. Mayo, F. Ramos, M. Saarela, R. E. Villa, R. J. Wallace, P. Wester, B. Glandorf, L. Herman, S. Karenlampi, J. Aguilera, M. Anguita, R. Brozzi, and J. Galobart. 2018. Guidance on the characterisation of microorganisms used as feed additives or as production organisms. EFSA J. 16:e05206. https://doi.org/10.2903/j.efsa.2018.5206.

Eid, J., A. Fehr, J. Gray, K. Luong, J. Lyle, G. Otto, P. Peluso, D. Rank, P. Baybayan, B. Bettman, A. Bibillo, K. Bjornson, B. Chaudhuri, F. Christians, R. Cicero, S. Clark, R. Dalal, A. deWinter, J. Dixon, M. Foquet, A. Gaertner, P. Hardenbol, C. Heiner, K. Hester, D. Holden, G. Kearns, X. Kong, R. Kuse, Y. Lacroix, S. Lin, P. Lundquist, C. Ma, P. Marks, M. Maxham, D. Murphy, I. Park, T. Pham, M. Phillips, J. Roy, R. Sebra, G. Shen, J. Sorenson, A. Tomaney, K. Travers, M. Trulson, J. Vieceli, J. Wegener, D. Wu, A. Yang, D. Zaccarin, P. Zhao, F. Zhong, J. Korlach, and S. Turner. 2009. Real-time DNA sequencing from single polymerase molecules. Science 323:133-138. https://doi.org/10.1126/ science.1162986.

Fei, Y., L. Li, Y. Zheng, D. Liu, Q. Zhou, and L. Fu. 2018. Characterization of Lactobacillus amylolyticus L6 as potential probiotics based on genome sequence and corresponding phenotypes. LWT 90:460-468. https://doi.org/10.1016/j.lwt.2017.12.028.

Fontana, A., I. Falasconi, P. Molinari, L. Treu, A. Basile, A. Vezzi, S. Campanaro, and L. Morelli. 2019. Genomic comparison of Lactobacillus helveticus strains highlights probiotic potentials. Front. Microbiol. 10:1380. https://doi.org/10.3389/fmicb.2019.01380.

Gibson, M. K., K. J. Forsberg, and G. Dantas. 2015. Improved annotation of antibiotic resistance determinants reveals microbial resistomes cluster by ecology. ISME J. 9:207-216. https://doi.org/ 10.1038/ismej.2014.106.

Hamon, E., P. Horvatovich, E. Izquierdo, F. Bringel, E. Marchioni, D. Aoudé-Werner, and S. Ennahar. 2011. Comparative proteomic analysis of Lactobacillus plantarum for the identification of key proteins in bile tolerance. BMC Microbiol. 11:63. https://doi.org/ 10.1186/1471-2180-11-63.

Hill, D., I. Sugrue, E. Arendt, C. Hill, C. Stanton, and R. P. Ross. 2017. Recent advances in microbial fermentation for dairy and health. F1000Res. 6(F1000 Faculty Rev):751. https://doi.org/10 $.12688 /$ f1000research.10896.1.

Huang, J., H. Fang, Z. C. Gai, J. Q. Mei, J. N. Li, S. Hu, C. J. Lv, W. R. Zhao, and L. H. Mei. 2018. Lactobacillus brevis CGMCC 1306 glutamate decarboxylase: Crystal structure and functional analysis. Biochem. Biophys. Res. Commun. 503:1703-1709. https://doi .org/10.1016/j.bbrc.2018.07.102.

International Dairy Federation. 2010. Milk and Milk Products-Determination of the Minimal Inhibitory Concentration (MIC) of Antibiotics Applicable to Bifidobacteria and Non-enterococcal Lactic Acid Bacteria (LAB). International Dairy Federation, Brussels, Belgium.

Iyer, R., T. M. Iverson, A. Accardi, and C. Miller. 2002. A biological role for prokaryotic ClC chloride channels. Nature 419:715-718. https://doi.org/10.1038/nature01000.

Jänsch, A., S. Freiding, J. Behr, and R. F. Vogel. 2011. Contribution of the NADH-oxidase (Nox) to the aerobic life of Lactobacillus sanfranciscensis DSM20451T. Food Microbiol. 28:29-37. https:// doi.org/10.1016/j.fm.2010.08.001.

Jia, B., A. R. Raphenya, B. Alcock, N. Waglechner, P. Guo, K. K. Tsang, B. A. Lago, B. M. Dave, S. Pereira, A. N. Sharma, S. Doshi, M. Courtot, R. Lo, L. E. Williams, J. G. Frye, T. Elsayegh, D. Sardar, E. L. Westman, A. C. Pawlowski, T. A. Johnson, F. S. L. Brinkman, G. D. Wright, and A. G. McArthur. 2017a. CARD 2017: Expansion and model-centric curation of the comprehensive antibiotic resistance database. Nucleic Acids Res. 45(D1):D566D573. https://doi.org/10.1093/nar/gkw1004.

Jia, F. F., L. J. Zhang, X. H. Pang, X. X. Gu, A. Abdelazez, Y. Liang, S. R. Sun, and X. C. Meng. 2017b. Complete genome sequence of bacteriocin-producing Lactobacillus plantarum KLDS1.0391, a probiotic strain with gastrointestinal tract resistance and adhesion to the intestinal epithelial cells. Genomics 109:432-437. https:// doi.org/10.1016/j.ygeno.2017.06.008.

Jiang, Y., and Z. Yang. 2018. A functional and genetic overview of exopolysaccharides produced by Lactobacillus plantarum. J. Funct. Foods 47:229-240. https://doi.org/10.1016/j.jff.2018.05.060.

Jordan, A., F. Åslund, E. Pontis, P. Reichard, and A. Holmgren. 1997. Characterization of Escherichia coli Nrdh a glutaredoxinlike protein with a thioredoxin-like activity profile. J. Biol. Chem. 272:18044-18050. https://doi.org/10.1074/jbc.272.29.18044.

Kang, T. S., D. R. Korber, and T. Tanaka. 2013. Influence of oxygen on NADH recycling and oxidative stress resistance systems in Lactobacillus panis PM1. AMB Express 3:10. https://doi.org/10.1186/ 2191-0855-3-10.

Kleerebezem, M., J. Boekhorst, R. van Kranenburg, D. Molenaar, O. P. Kuipers, R. Leer, R. Tarchini, S. A. Peters, H. M. Sandbrink, M. W. E. J. Fiers, W. Stiekema, R. M. K. Lankhorst, P. A. Bron, S. M. Hoffer, M. N. N. Groot, R. Kerkhoven, M. de Vries, B. Ursing, W. M. de Vos, and R. J. Siezen. 2003. Complete genome sequence of Lactobacillus plantarum WCFS1. Proc. Natl. Acad. Sci USA 100:1990-1995. https://doi.org/10.1073/pnas.0337704100.

Koskenniemi, K., K. Laakso, J. Koponen, M. Kankainen, D. Greco, P. Auvinen, K. Savijoki, T. A. Nyman, A. Surakka, T. Salusjärvi, W. M. de Vos, S. Tynkkynen, N. Kalkkinen, and P. Varmanen. 2011. Proteomics and transcriptomics characterization of bile stress response in probiotic Lactobacillus rhamnosus GG. Mol. Cell. Proteomics 10:M110.002741. https://doi.org/10.1074/mcp .M110.002741.

Ladero, V., E. Cañedo, M. Pérez, M. C. Martín, M. Fernández, and M. A. Alvarez. 2012. Multiplex qPCR for the detection and quantification of putrescine-producing lactic acid bacteria in dairy products. Food Control 27:307-313. https://doi.org/10.1016/j.foodcont 2012.03.024.

Lambert, J. M., R. S. Bongers, W. M. de Vos, and M. Kleerebezem. 2008. Functional analysis of four bile salt hydrolase and penicillin acylase family members in Lactobacillus plantarum WCFS1. Appl. Environ. Microbiol. 74:4719-4726. https://doi.org/10.1128/AEM .00137-08.

Lee, I. C., G. Caggianiello, I. I. van Swam, N. Taverne, M. Meijerink, P. A. Bron, G. Spano, and M. Kleerebezem. 2016a. Strain-specific features of extracellular polysaccharides and their impact on Lactobacillus plantarum-host interactions. Appl. Environ. Microbiol. 82:3959-3970. https://doi.org/10.1128/AEM.00306-16.

Lee, K. W., J. M. Shim, S.-K. Park, H.-J. Heo, H.-J. Kim, K.-S. Ham, and J. H. Kim. 2016b. Isolation of lactic acid bacteria with probiotic potentials from kimchi, traditional Korean fermented vegetable. Lebensm. Wiss. Technol. 71:130-137. https://doi.org/10 .1016/j.lwt.2016.03.029.

Li, L., X. Wen, Z. Wen, S. Chen, L. Wang, and X. Wei. 2018. Evaluation of the biogenic amines formation and degradation abilities of Lactobacillus curvatus from Chinese bacon. Front. Microbiol. 9:1015. https://doi.org/10.3389/fmicb.2018.01015.

Li, P., X. Li, Q. Gu, X. Y. Lou, X. M. Zhang, D. F. Song, and C. Zhang. 2016. Comparative genomic analysis of Lactobacillus plantarum ZJ316 reveals its genetic adaptation and potential probiotic profiles. J. Zhejiang Univ. Sci. B 17:569-579. https://doi.org/10 $.1631 /$ jzus.B1600176. 
Liu, C., Z. Y. Zhang, K. Dong, J. P. Yuan, and X. K. Guo. 2009. Antibiotic resistance of probiotic strains of lactic acid bacteria isolated from marketed foods and drugs. Biomed. Environ. Sci. 22:401-412. https://doi.org/10.1016/S0895-3988(10)60018-9.

Liu, C. J., R. Wang, F. M. Gong, X. F. Liu, H. J. Zheng, Y. Y. Luo, and X. R. Li. 2015. Complete genome sequences and comparative genome analysis of Lactobacillus plantarum strain 5-2 isolated from fermented soybean. Genomics 106:404-411. https://doi.org/ 10.1016/j.ygeno.2015.07.007.

Liu, M., A. Nauta, C. Francke, and R. J. Siezen. 2008. Comparative genomics of enzymes in flavor-forming pathways from amino acids in lactic acid bacteria. Appl. Environ. Microbiol. 74:4590-4600. https://doi.org/10.1128/AEM.00150-08.

Liu, Y. J., Y. Q. Zhang, Y. Gao, H. Y. Li, G. Q. Mu, and Y. F. Tuo. 2019. Studies on the antioxidative activity of exopolysaccharide from Lactobacillus strains. Journal of Chinese Institute of Food Science and Technology 19:21-35.

Lombard, V., H. Golaconda Ramulu, E. Drula, P. M. Coutinho, and B. Henrissat. 2014. The carbohydrate-active enzymes database (CAZy) in 2013. Nucleic Acids Res. 42(D1):D490-D495. https:// doi.org/10.1093/nar/gkt1178.

Lv, L. X., R. Yan, H. Y. Shi, D. Shi, D. Q. Fang, H. Y. Jiang, W. R. Wu, F. F. Guo, X. W. Jiang, S. L. Gu, Y. B. Chen, J. Yao, and L. J. Li. 2017. Integrated transcriptomic and proteomic analysis of the bile stress response in probiotic Lactobacillus salivarius LI01. J. Proteomics 150:216-229. https://doi.org/10.1016/j.jprot.2016 .08 .021 .

Marshall, V. M. 1987. Fermented milks and their future trends: I. Microbiological aspects. J. Dairy Res. 54:559-574. https://doi.org/10 .1017/S0022029900025760.

Meng, J., X. Zhu, S. M. Gao, Q. X. Zhang, Z. Sun, and R. R. Lu. 2014. Characterization of surface layer proteins and its role in probiotic properties of three Lactobacillus strains. Int. J. Biol. Macromol. 65:110-114. https://doi.org/10.1016/j.ijbiomac.2014.01.024.

Monteagudo-Mera, A., R. A. Rastall, G. R. Gibson, D. Charalampopoulos, and A. Chatzifragkou. 2019. Adhesion mechanisms mediated by probiotics and prebiotics and their potential impact on human health. Appl. Microbiol. Biotechnol. 103:6463-6472. https: //doi.org/10.1007/s00253-019-09978-7.

Mu, G., Y. Gao, Y. Tuo, H. Li, Y. Zhang, F. Qian, and S. Jiang. 2018. Assessing and comparing antioxidant activities of lactobacilli strains by using different chemical and cellular antioxidant methods. J. Dairy Sci. 101:10792-10806. https://doi.org/10.3168/ jds.2018-14989.

Mu, G., H. Li, Y. Tuo, Y. Gao, and Y. Zhang. 2019. Antioxidative effect of Lactobacillus plantarum Y44 on 2, 2'-azobis (2-methylpropionamidine) dihydrochloride (ABAP)-damaged Caco-2 cells. J. Dairy Sci. 102:6863-6875. https://doi.org/10.3168/jds.2019-16447.

Müller, M., S. Reiß, R. Schlüter, U. Mäder, A. Beyer, W. Reiß, J. Marles-Wright, R. J. Lewis, H. Pförtner, U. Völker, K. Riedel, M. Hecker, S. Engelmann, and J. Pané-Farré. 2014. Deletion of membrane-associated Asp 23 leads to upregulation of cell wall stress genes in Staphylococcus aureus. Mol. Microbiol. 93:1259-1268.

O'Connell-Motherway, M., D. van Sinderen, F. Morel-Deville, G. F. Fitzgerald, S. D. Ehrlich, and P. Morel. 2000. Six putative twocomponent regulatory systems isolated from Lactococcus lactis ssp. cremoris MG1363. Microbiology 146:935-947.

Odamaki, T., J. Z. Xiao, S. Yonezawa, T. Yaeshima, and K. Iwatsuki. 2011. Improved viability of bifidobacteria in fermented milk by cocultivation with Lactococcus lactis subspecies lactis. J. Dairy Sci. 94:1112-1121. https://doi.org/10.3168/jds.2010-3286.

Petrova, M. I., J. M. Macklaim, S. Wuyts, T. Verhoeven, J. Vanderleyden, G. B. Gloor, S. Lebeer, and G. Reid. 2018. Comparative genomic and phenotypic analysis of the vaginal probiotic Lactobacillus rhamnosus GR-1. Front. Microbiol. 9:1278. https://doi.org/ 10.3389/fmicb.2018.01278.

Ren, J., K. Sun, Z. Wu, J. Yao, and B. Guo. 2011. All 4 Bile salt hydrolase proteins are responsible for the hydrolysis activity in Lactobacillus plantarum ST-III. J. Food Sci. 76:M622-M628. https: //doi.org/10.1111/j.1750-3841.2011.02431.x.
Richter, M., R. Rosselló-Móra, F. Oliver Glöckner, and J. Peplies. 2016. JSpeciesWS: A web server for prokaryotic species circumscription based on pairwise genome comparison. Bioinformatics 32:929-931. https://doi.org/10.1093/bioinformatics/btv681.

Rodrigo-Torres, L., A. Yépez, R. Aznar, and D. R. Arahal. 2019. Genomic insights into five strains of Lactobacillus plantarum with biotechnological potential isolated from chicha, a traditional maizebased fermented beverage from Northwestern Argentina. Front. Microbiol. 10:2232. https://doi.org/10.3389/fmicb.2019.02232.

Satokari, R. 2019. Modulation of gut microbiota for health by current and next-generation probiotics. Nutrients 11:1921. https:// doi.org/10.3390/nu11081921.

Seddik, H. A., F. Bendali, F. Gancel, I. Fliss, G. Spano, and D. Drider. 2017. Lactobacillus plantarum and its probiotic and food potentialities. Probiotics Antimicrob. Proteins 9:111-122. https://doi .org/10.1007/s12602-017-9264-z.

Stefanovic, E., and O. McAuliffe. 2018. Comparative genomic and metabolic analysis of three Lactobacillus paracasei cheese isolates reveals considerable genomic differences in strains from the same niche. BMC Genomics 19:205. https://doi.org/10.1186/s12864-018 $-4586-0$.

Stothard, P., and D. S. Wishart. 2005. Circular genome visualization and exploration using CGView. Bioinformatics 21:537-539. https: //doi.org/10.1093/bioinformatics/bti054.

Suez, J., N. Zmora, and E. Elinav. 2020. Probiotics in the next-generation sequencing era. Gut Microbes 11:77-93.

Tatusova, T., M. DiCuccio, A. Badretdin, V. Chetvernin, E. P. Nawrocki, L. Zaslavsky, A. Lomsadze, K. D. Pruitt, M. Borodovsky, and J. Ostell. 2016. NCBI prokaryotic genome annotation pipeline. Nucleic Acids Res. 44:6614-6624. https://doi.org/10.1093/ nar/gkw569.

Todorov, S. D., and B. D. G. D. M. Franco. 2010. Lactobacillus plantarum: Characterization of the species and application in food production. Food Rev. Int. 26:205-229. https://doi.org/10.1080/ 87559129.2010.484113.

Wen, L., G. Zheng, L. You, A. M. Abbasi, T. Li, X. Fu, and R. H. Liu. 2016. Phytochemical profiles and cellular antioxidant activity of Malus doumeri (bois) chevalier on 2,2'-azobis (2-amidinopropane) dihydrochloride (ABAP)-induced oxidative stress. J. Funct. Foods 25:242-256. https://doi.org/10.1016/j.jff.2016.06.004.

Xiong, Z. Q., L. H. Kong, P. F. H. Lai, Y. J. Xia, J. C. Liu, Q. Y. Li, and L. Z. Ai. 2019. Genomic and phenotypic analyses of exopolysaccharide biosynthesis in Streptococcus thermophilus S-3. J. Dairy Sci. 102:4925-4934. https://doi.org/10.3168/jds.2018-15572.

Zankari, E., H. Hasman, S. Cosentino, M. Vestergaard, S. Rasmussen, O. Lund, F. M. Aarestrup, and M. V. Larsen. 2012. Identification of acquired antimicrobial resistance genes. J. Antimicrob. Chemother. 67:2640-2644. https://doi.org/10.1093/jac/dks261.

Zhang, W., H. Ji, D. Zhang, H. Liu, S. Wang, J. Wang, and Y. Wang. 2018. Complete genome sequencing of Lactobacillus plantarum ZLP001, a potential probiotic that enhances intestinal epithelial barrier function and defense against pathogens in pigs. Front. Physiol. 9:1689.

Zhang, Z. Y., C. Liu, Y. Z. Zhu, Y. X. Wei, F. Tian, G. P. Zhao, and X. K. Guo. 2012. Safety assessment of Lactobacillus plantarum JDM1 based on the complete genome. Int. J. Food Microbiol. 153:166-170. https://doi.org/10.1016/j.ijfoodmicro.2011.11.003.

Zschiedrich, C. P., V. Keidel, and H. Szurmant. 2016. Molecular mechanisms of two-component signal transduction. J. Mol. Biol. 428:3752-3775. https://doi.org/10.1016/j.jmb.2016.08.003.

\section{ORCIDS}

Yuan Gao $\odot$ https://orcid.org/0000-0002-3931-4272 Yujun Liu ๑ https://orcid.org/0000-0001-6114-7178 Heping Zhang (ㄴ) https://orcid.org/0000-0003-4329-8006 Guangqing Mu ๑ https://orcid.org/0000-0001-9356-753X Yanfeng Tuo (ㄴ) https://orcid.org/0000-0001-7255-3753 